\title{
Stakeholder perceptions regarding the environmental and socio-economic impacts of the Algarve artificial reefs
}

\author{
Jorge Ramos $\cdot$ Miguel N. Santos • \\ David Whitmarsh · Carlos C. Monteiro
}

(C) Springer Science+Business Media B.V. 2007

\begin{abstract}
The artificial reef (AR) complex of the Algarve (Southern Portugal), deployed for the purpose of restoring and enhancing fisheries resources, is currently the largest structure of its kind in Europe, extending for over $43.5 \mathrm{~km}^{2}$. Such a structure can be expected to have had both positive and negative impacts. To evaluate the overall perception of the effects of deployment, a survey of stakeholders' opinions was undertaken based on a set of questions addressing various dimensions (environmental, social, and economic). The survey covered 44 key-stakeholder representatives distributed in six groups: commercial fishermen associations, anglers associations and clubs, diving schools and clubs, fisheries and environmental administrators, natural and social scientists, and local council representatives in the fisheries
\end{abstract}

Guest editors: G. Relini \& J. Ryland Biodiversity in Enclosed Seas and Artificial Marine Habitats

J. Ramos · M. N. Santos $(\bowtie)$ C C. C. Monteiro Instituto Nacional da Investigação Agrária e das Pescas/IPIMAR Centro Regional de Investigação Pesqueira do Sul (CRIPSul), Av. 5 de Outubro s/n, 8700-305 Olhão, Portugal

e-mail: mnsantos@cripsul.ipimar.pt

J. Ramos · D. Whitmarsh

CEMARE, University of Portsmouth, Boathouse no 6, College Road, HM Naval Base, Portsmouth PO1 3LJ, UK and/or environmental sectors. The opinions of stakeholders were measured using summated rating scales. The results obtained reflect the most important issues be impacted and the possibility of using them as indicators of relative success or failure. From a total of 12 factor-sets of impacts, the results showed that in general the environmentally related were the ones having had the most positive results. The overall perception of the environmental factor-sets specified as the 'deployment area use' revealed that the artificial reefs were an incentive to users and that the structures were perceived as a satisfactory tool to support the fishery and its management. In both cases divers were the strongest supporters. A closer look at the results presented in the form of an AMOEBA plot showed that there were other factor-sets perceived as impacting positively in other dimensions. Such examples are the factor-sets 'opinion' and 'production and benefits' lying respectively in the social and economic dimensions. The latter factor-set was even the only one having the support of five out of six stakeholder-types. As expected, in general different stakeholder-types take somewhat different positions and attitudes towards AR impacts: usually scientists are the most optimistic, whereas fishermen take the most sceptic view.

Keywords Artificial reefs (ARs) - Impact analysis · Fisheries · Indicators for management 


\section{Introduction}

The Algarve (southern Portuguese coast) is a region that has been highly impacted by a multipurpose active fleet exploiting fisheries resources (Moniz et al., 2000). These resources attain on average some of the best market prices in the country for many fish species as reported by the Fisheries and Aquaculture Directorate (DGPA, 2002), a feature which acts as an incentive to keep fishermen employed in the activity. A socioeconomic characteristic of the region is that a high proportion of people depend on fishing for their livelihoods (Moniz, 1997; Moniz et al., 2000). In 2003, over 3,500 fishermen were engaged in sea-fisheries in the region (DGPA, 2004), the majority of whom fished all year round. A survey by DGPA (2000) revealed that fishing tends to be a very erratic activity, with many fishers taking advantage of other economic activities linked with tourism in order to provide an additional or substitute source of income during the summer season. Apart from commercial fishing there are many other activities in the Algarve region that are directly dependent on fish resources, notably angling and diving. The former is practised by enthusiasts from local clubs all year round, but particularly by the end of the summer and fall; whereas the latter is practised mainly during warmer months, i.e., April to September.

In recent years a number of strategies have been developed to address the misuse of fish resources that has occurred in the past. Artificial reefs (ARs) represent one such approach, and indeed have become commonly used world wide to aggregate fish species in the marine environment (Aabel et al., 1996). In the Algarve, after a successful experience with pilot ARs (Santos \& Monteiro, 1997, 1998), it was decided that reefs should be deployed on a larger scale throughout the region, but particularly in the windward area (Monteiro \& Santos, 2000). The main reason was that in this area there is less abundance of rocky bottoms, having instead, muddy or sandy bottoms, the latter being a prerequisite for $\mathrm{AR}$ deployment decision. The deployment of the main program structures started in 1996 and was concluded by summer 2003. The Algarve's ARs were created with traditional small-scale fishing use in mind (Santos \& Monteiro, 2001). The initial objectives of the program were to: (a) promote bio-diversity; (b) protect juveniles of commercial species; (c) manage coastal resources; (d) reduce fishing exploitation costs; (e) recover fishing resources; (f) create fishing zones; and (g) adapt gear and fishing strategies to resources availability. The program scope was wide, encompassing both economic and social objectives, but having in mind mainly an environmental focus.

To date, scientific evidence shows that there has been an increase in abundance of economically-important fish species on the pilot ARs surveyed since their deployment in the early 1990s (Santos \& Monteiro, 1997, 1998; Whitmarsh et al., 2004). Over this period, users have been accumulating greater empirical knowledge of the effects of ARs, and this has undoubtedly influenced both their behaviour (e.g. fishing patterns) and attitudes towards the reef programme as a whole. These attitudes may, of course, be negative as well as positive. Experience suggests that ARs typically give rise to a range of impacts, not all of which may be perceived as beneficial by users. For example, while CPUE and incomes may be enhanced, at least in the short term, the attraction of more vessels is likely to increase user conflict (Milon, 1989; Samples, 1989; Galvez, 1991; Murray \& Betz, 1994). The aim of this paper is to investigate the local community's perceptions of the Algarve artificial reefs, and to see to what extent people regard the reef programme as having been successful. We contend that the opinions of stakeholders are crucial in this context. When there is a consensus amongst key individuals and groups over the objectives of ARs, it becomes easier to establish whether these objectives have been adequately addressed and how close they are to being reached. By contrast, lack of consensus makes it more difficult to derive a clear and unambiguous indicator for evaluating performance. Stakeholder opinions towards socio-economic as well as environmental objectives need to be considered, and this sort of data typically has to be collected via surveys (Milon et al., 2000). Such information is important to fish managers since they would like to know which impacts are 
acceptable and which are not. To carry out this sort of study it is important to consult properly all the local stakeholders and interest groups. Studies which have examined the impact of artificial reefs, particularly as they involve stakeholders, have commonly concerned the 'rigs-to-reefs' conversion of obsolete oil platforms to other uses (Reggio et al., 1986; McGurrin \& Fedler, 1989; Reggio, 1989; Cripps \& Aabel, 2002).

In this paper we have undertaken a simple analysis of perceived impacts by consulting a panel made up of different key-stakeholders involved in the AR deployment process and its use. The panel's overall perception of the effects resulting from AR deployment in the Algarve south coast may help resource managers to use achieved results in order to find out trade-offs between policy objectives.

\section{Materials and methods}

Though the reef deployment programme was only completed in 2003, the presence of artificial habitats since the early 1990s is acknowledged to have had a biological impact. While it is essential to explore the economic implications of this, particularly in respect of measurable quantities such as catches and incomes, it is important also to find out how far people regard the reef programme as successful along a wide spectrum of performance criteria. A number of techniques may potentially be used to measure stakeholder attitudes (Robson, 2002), and the particular approach adopted here is outlined below.

\section{Questionnaire survey}

As a first step in the study, three dimensions expected to be impacted by reef deployment were selected: environmental, social, and economic. For each dimension, factors likely to be affected by deployment were identified, from which an item-pool was constructed (Bell, 1987; Robson, 2002) which included all the perceived predefined impacts. The item-pool consisted of 54 ambiguous-free relevant items to be included in the survey of respondents' opinions (Table 1). The item-pool was then adapted to a specific questionnaire addressed to a range of people with

Table 1 Brief description of each of the 12 factor-sets and the number of impacts addressed to the key-stakeholders

\begin{tabular}{|c|c|c|c|}
\hline Dimension & Factor-set & Brief description & $\begin{array}{l}\text { No. } \\
\text { items }\end{array}$ \\
\hline \multirow[t]{4}{*}{ Environmental } & A. Deployment area use & $\begin{array}{l}\text { To assess stakeholders' perception on the use } \\
\text { that can be found in the area. }\end{array}$ & 4 \\
\hline & $\begin{array}{l}\text { B. Ecological impact and } \\
\text { bio-diversity }\end{array}$ & $\begin{array}{l}\text { Effects caused on the species, namely their } \\
\text { aggregation and protection after reef deployment. }\end{array}$ & 5 \\
\hline & C. Pollution & $\begin{array}{l}\text { The contribution of the structures as a factor } \\
\text { of pollution to the environment (water or sediment). }\end{array}$ & 3 \\
\hline & D. Fishery and management & $\begin{array}{l}\text { ARs as a management tool for fisheries } \\
\text { (traditional fishing, off-shore aquaculture, etc). }\end{array}$ & 6 \\
\hline \multirow[t]{4}{*}{ Social } & $\begin{array}{l}\text { E. Demography and } \\
\text { employment }\end{array}$ & $\begin{array}{l}\text { Signs of changes in social aspects (people migration, } \\
\text { employment, and social benefits). }\end{array}$ & 3 \\
\hline & $\begin{array}{l}\text { F. Enforcement and } \\
\text { communication }\end{array}$ & $\begin{array}{l}\text { The need to establish sea use rules and communication } \\
\text { between the different players. }\end{array}$ & 4 \\
\hline & G. Opinion & $\begin{array}{l}\text { How is the AR' deployment perceived by stakeholders } \\
\text { and the public in general. }\end{array}$ & 5 \\
\hline & H. Conflicts & $\begin{array}{l}\text { Possibilities of conflicts occurrence between the different } \\
\text { stakeholders involved. }\end{array}$ & 6 \\
\hline \multirow[t]{4}{*}{ Economic } & I. Production and benefits & $\begin{array}{l}\text { To evaluate the chances of extra catches and returns after reef } \\
\text { deployment. }\end{array}$ & 4 \\
\hline & J. Costs to society & Awareness of the costs involved in the reef deployment process. & 5 \\
\hline & K. Changes in local economy & $\begin{array}{l}\text { Signs of changes in the local economy in all the sectors of activity } \\
\text { after reef deployment. }\end{array}$ & 5 \\
\hline & L. Safety at sea & $\begin{array}{l}\text { Reefs contribution to promote safer fishing activities in their } \\
\text { deployment area. }\end{array}$ & 4 \\
\hline
\end{tabular}


different perceptions and educational levels. The questionnaire was pre-tested and adjusted. Prior contact was established both by post or e-mail. This was accompanied by an introductory letter explaining the objectives of the proposed work, and an informative memorandum including the purposes of the ARs and their structure, organisation and location along the south-coast. The questionnaires were sent directly to each representative by hand or via post mail, and were addressed to the highest representative of each body/institution, or to the person used to work with fisheries or environmental issues. The survey was carried out approximately one year after the conclusion of the deployment phase, during a period of forty-five days (from the middle of May to the end of June 2004).

\section{Conceptual framework and stakeholders}

Though the consultation was principally a retrospective assessment of the performance of the established in situ reefs, the responses given to the questions also give an indication of the expected effects of the newly-established reefs and how far they are likely to meet the needs of stakeholders. Indeed, the attitudes of affected parties regarding the acceptability of ARs should be an element in any decision regarding future reef deployment, particularly as regards design and location. In choosing respondents to take part in the survey, individuals were pre-selected from a key-stakeholder database created from the regional yellow pages and from a fisheries events invitation list. The panel was constructed from key-stakeholders based on their agreement to take part in the survey.

The survey was addressed to representatives of: (a) fishermen associations; (b) anglers clubs and associations; (c) divers clubs; (d) environmental and fisheries administrations; (e) natural, social and economic scientists; and (f) others as borough council representatives in the environmental and/or fisheries areas. The key-stakeholders panel consulting approach was similar to the one described by McKinnon \& Forster (2000), where: (i) items were kept simple, and averaged member's views encouraging a consensus within the same institution; (ii) information was col- lected by questionnaire, without using interviews or subject discussion; and, (iii) anonymity was guaranteed to the members of the panel.

Each one of the six stakeholder-types presented six to eight representatives. In order to understand stakeholders' involvement with the ARs, representatives were divided into two groups: those who knew the structures either by using them or by being involved since the pre-deployment process, and the others whose knowledge was solely by other means (e.g. by the media). The first three types of panel members represent the direct or potential users, whereas the other three are usually involved in the ARs process but mostly as institutional representatives.

The impact assessment validation

Key-stakeholders used 5-point Likert scales to state their positions about impacts (Murray \& Betz, 1994; Cripps \& Aabel, 2002; Kennish et al., 2002). Perceptions/attitudes were then measured using summated rating scales. Items were graded accordingly to the probable perturbations in the marine system caused by reef deployment as well the effects on the fishing communities nearby. After collecting all questionnaires, impacts of the AR deployment were defined according to their scores and the analyses carried out by dimension, stakeholder type, factor-sets, and the most meaningful items. To evaluate the level of the impact it was important to define a priori what constituted a 'positive impact', since this underlay the whole concept and measurement of success in policy terms.

The survey made use of an AMOEBA plot, which is a graphical device that uses a 'radar' diagram. Though the approach is simplistic it has the advantage of representing to respondents (usually managers and policy makers) the impact of an intervention in a clear and easily understandable manner (Ten Brink et al., 1991). In the current study an AMOEBA plot was used consisting of three areas: inner (negative impacts), middle (no evident impact), and outer (positive impacts). The AMOEBA reading shows that the perception on the AR complex impact assessed over 12 factor-sets is not expressed as a function of others (discrete variables). In this way we can 
obtain a visual impression of whether an impact on any one dimension or factor has been positive or negative.

The results obtained concerning ARs' impacts after deployment have particular significance for stakeholders. The analysis was undertaken by separating the panel of stakeholders according the group of interests. To demonstrate the differences in stakeholders' positioning, hypotheses were tested for the whole impact using a simple $t$-test (Zar, 1996). The $t$-test was carried out for the analyses on dimension, factor-set, and stakeholder-type. It was decided to work on a percentage basis where the overall score had three critical thresholds: scores over 66.7 implied that the effect was positive, those falling between 33.3 and 66.7 signified that the impacts were largely neutral, while those below 33.3 were interpreted as negative. For each item individually summated rating scales were also defined showing the top and bottom impacted ones.

\section{Results}

Key-stakeholders' characteristics

The total number of contacted stakeholders representing regional entities was 53. Of these, 9 stakeholders explicitly declined to collaborate, did not answer the calls, did not fill the questionnaire during the stipulated time, or simply filled the questionnaire in an invalid way (Table 2). The final panel consisted in 44 respondents, where 28

Table 2 The key-stakeholders contacted and its relationship with the ARs

\begin{tabular}{lllll}
\hline Contacted $(n=53)$ & \multicolumn{3}{l}{} \\
\hline Stakeholder type & Denied & \multicolumn{2}{l}{ Agreed } \\
\cline { 3 - 5 } & & Total & AR experience \\
\cline { 3 - 5 } & & & Heard & Known \\
& & & 0 & 7 \\
Fishermen & 2 & 7 & 2 & 5 \\
Anglers & 2 & 7 & 1 & 5 \\
Divers & 1 & 6 & 2 & 6 \\
Administrators & 2 & 8 & 5 & 3 \\
Scientists & 1 & 8 & 6 & 2 \\
Others & 1 & 8 & 16 & 28 \\
Total & 9 & 44 & & \\
\hline
\end{tabular}

knew already the structures, and 16 were just somewhat familiarised with artificial reefs built off the Algarve's coast. The most familiarised group was fishermen, and the least one was the group of borough council representatives.

Key-stakeholders' perception

In terms of impact perception, the majority of stakeholders were positive concerning the environmental impact caused by ARs. Stakeholders who had first-hand experience of the structures were even more optimistic than those who had simply heard about them. Concerning the environmental terms, around $60 \%$ of the answers showed that reef deployment had made a positive contribution, against $20 \%$ believing the impact was negative. By contrast, for social and economic effects both types of stakeholders were more cautious in making statements about the potential impacts. The areas corresponding to the neutral position reflected in some way stakeholders' difficulty in formulating judgements. Around one third of the social and economic dimensions remain in this position (Fig. 1). For the economic and social dimensions, less than $50 \%$ of the answers were accounted as positive and more than $20 \%$ negative.

Key-stakeholders' general positioning and dimension analysis

Despite the differences found between those stakeholders who knew the reefs from first-hand experience and those that had only heard about them, it can be confirmed that the entire panel thought that the most important positive impacts belonged to the environmental dimension (Fig. 2). The hypotheses tested showed that only fishermen and anglers were not sure about the environmental overall impact of the ARs. By contrast, divers and scientists were the most optimistic (Table 3). Anglers, divers, and administrators considered that economic impacts overshadowed social impacts, whereas scientists and others claimed the opposite. In addition, fishermen representatives were the most sceptical among all concerning to the economic dimension of the reefs, contrasting with administrators who 


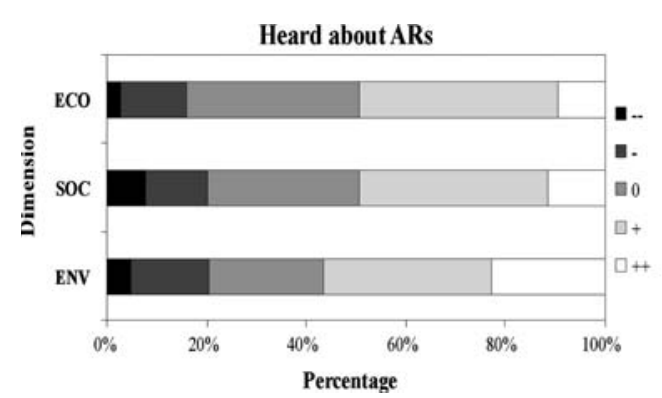

Fig. 1 Stakeholders' perception about impacts: (a) Stakeholders who only heard about ARs ( $n=864$ answers), (b) stakeholders that know ARs ( $n=1,512$ answers). "Minus" signs represent the percentage of impacts perceived as negative. "Plus" signs represent the percentage of impacts

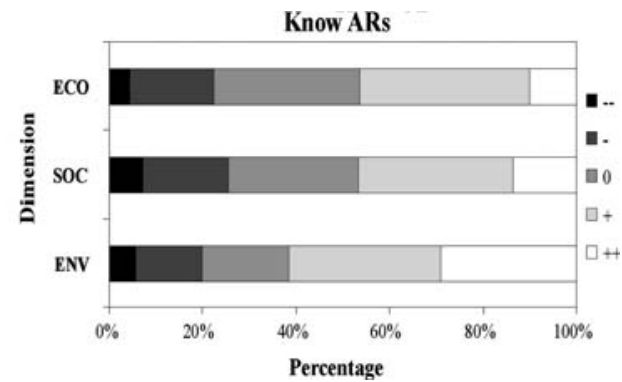

perceived as positive. Double minus/plus mean respectively high improbability/probability of occurrence. The "zero" represents answers with no clear position taken or perceived by stakeholders. Legend: ENV, Environmental; SOC, Social; ECO, Economic
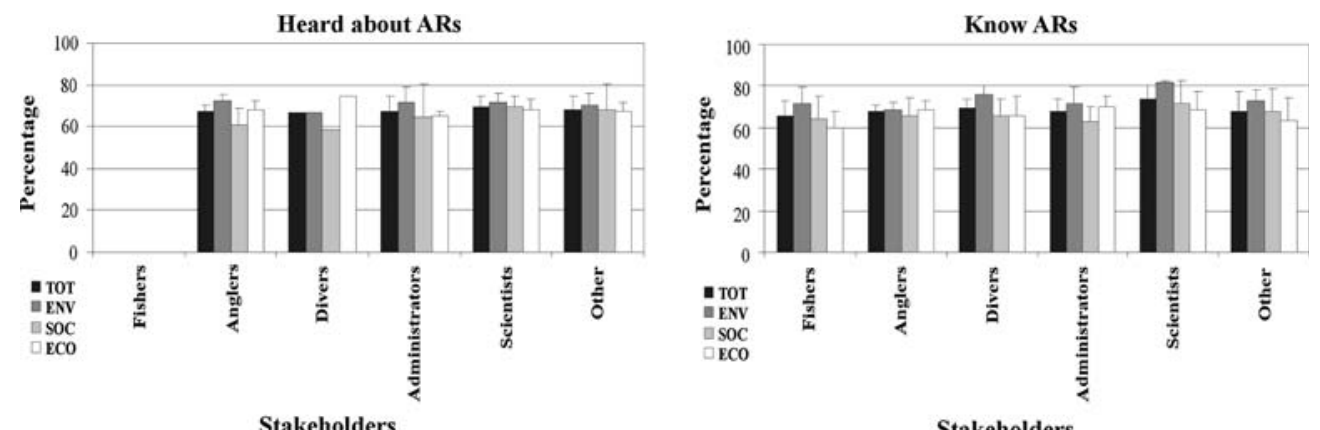

Fig. 2 Stakeholders' positioning about impacts caused in each dimension. Legend: ENV, Environmental; SOC, Social; ECO, Economic; TOT, All previous three dimensions together

strongly supported their economic role. Scientists were the most favourably inclined towards the social role of the reefs.

\section{Factor-sets analysis}

By disaggregating each dimension in their factorsets through an AMOEBA plot, it was possible to perceive important impacts detected by the entire panel of stakeholders (Fig. 3). A refinement of the AMOEBA plot showed that among the 12 factors, only four can be considered as positively significant (Table 4). In the environmental dimension, the only factor not having a visible positive impact is related to 'pollution', whereas all the other factors are positively accepted (however, 'ecological impact and bio-diversity' was rejected by the $t$-test). The social dimension, by contrast, showed only a strong positive factor related with the 'opinion' demonstrating that these structures were generally welcomed. For its part, the economic dimension seemed to have factor-sets perceived sceptically in terms of some factors (for example 'costs to society' and 'safety at sea') but more favourably in terms of others (e.g. 'production and benefits').

Table 3 Statistical results using $t$-test for impacted dimensions. ' ++ ' for $\mathrm{p}<0.01$, '+' for $P<0.05$, and the 'n.s.' for non-significant results

\begin{tabular}{|c|c|c|c|c|}
\hline \multirow[t]{2}{*}{ Stakeholder } & \multicolumn{4}{|l|}{ Dimension } \\
\hline & Environmental & Social & Economic & All \\
\hline Fishermen & n.s. & n.s. & n.s. & n.s. \\
\hline Anglers & n.s. & n.s. & n.s. & n.s. \\
\hline Divers & ++ & n.s. & n.s. & n.s. \\
\hline Administrators & + & n.s. & n.s. & n.s. \\
\hline Scientists & ++ & n.s. & n.s. & + \\
\hline Others & + & n.s. & n.s. & n.s. \\
\hline
\end{tabular}


Fig. 3 The AMOEBA plot showing the 12 factor-sets of impacts

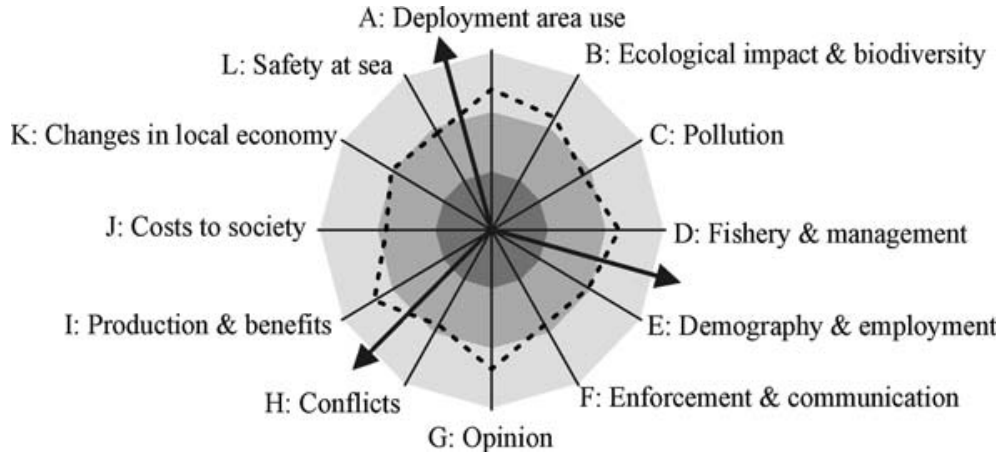

Key-stakeholders by factor-set

The disaggregation of the dimensions by factorset and the entire stakeholder panel by stakeholder-types shows that groups are not identical in their assessment of the impacts (Table 5). After putting together all stakeholders results by factor-set it appears that fishermen were the most sceptical concerning evident positive impacts. For their part, administrators are positive about just two fundamental socio-economic aspects of the reefs: the structures' acceptance and their role as revenue generators. In contrast to the previous groups, divers are the ones believing that four out of 12 impacted factor-sets are positive.

The most positively impacted factor-set was within the environmental dimension and related to the 'deployment area use', where three of the stakeholder-types supported the suggestion that

Table 4 Simple t-test statistics for the AMOEBA-approach refinement. ' ++ ' for $P<0.01$, '+' for $P<0.05$, and the 'n.s.' for non-significant results

\begin{tabular}{lll}
\hline Dimension & Factor-set & Statistics \\
\hline Environmental & A. Deployment area use & ++ \\
& B. Ecological impact and bio- & n.s. \\
& $\quad$ diversity & \\
& C. Pollution & n.s. \\
D. Fishery and management & + \\
Social & E. Demography and & n.s. \\
& $\quad$ employment & \\
& F. Enforcement and & n.s. \\
& $\quad$ communication & \\
& G. Opinion & ++ \\
H. Conflicts & n.s. \\
& I. Production and benefits & ++ \\
& J. Costs to society & n.s. \\
& K. Changes in local economy & n.s. \\
& L. Safety at sea & n.s. \\
\hline
\end{tabular}

ARs will attract more users to sites. Another factor-set showing favourable results concerned the social dimension, and related to the 'opinion' about AR deployment. Here were found four out of six stakeholder-types with a confident attitude/ opinion, while only fishermen and anglers remained unconvinced. The factor-set believed to have had a demonstrated positive effect was the 'production and benefits', with five out of six stakeholder types being strongly favourable to it. Fishermen alone were sceptical or did not reveal their position.

Factor-sets that do not show any significance can also give some clues about AR impact. For instance, environmentally it seems that ARs are not regarded as a source of pollution, since none of the stakeholder-types held a clear position on this aspect. The same situation was found with respect to the role of ARs as a tool to improve 'fishery and management', since apart from divers no other group revealed an attitude that was either strongly positive or negative. Socially it seems that AR deployment is not a significant contributor to 'demography and employment' in the region, a result which is consistent with the belief that ARs will not significantly impact on the local economy.

\section{Key-stakeholders agreed impacts}

The survey results enable us to produce a hierarchy of items most significantly affected by the deployment of the reefs (Table 6). Ratings are indicators of stakeholders' sensitivity to impacts.

On the positive side, the overall perception is that: ARs promote a specific habitat enriched with several different species, promoting 
Table 5 Simple $t$-test statistics showing stakeholder type by factor-set. ' ++ ' for $P<0.01$, '+' for $P<0.05$, and the 'n.s.' for non-significant results

\begin{tabular}{|c|c|c|c|c|c|c|c|c|c|c|c|c|}
\hline \multirow[t]{3}{*}{ Stakeholder } & \multicolumn{12}{|c|}{ Dimension } \\
\hline & \multicolumn{4}{|c|}{ Environmental } & \multicolumn{4}{|c|}{ Social } & \multicolumn{4}{|c|}{ Economic } \\
\hline & A & $\mathrm{B}$ & $\mathrm{C}$ & $\mathrm{D}$ & $\mathrm{E}$ & $\mathrm{F}$ & G & $\mathrm{H}$ & I & $\mathrm{J}$ & $\mathrm{K}$ & $\mathrm{L}$ \\
\hline Fishermen & n.s. & n.s. & n.s. & n.s. & n.s. & n.s. & n.s. & n.s. & n.s. & n.s. & n.s. & n.s. \\
\hline Anglers & + & n.s. & n.s. & n.s. & n.s. & n.s. & n.s. & n.s. & + & n.s. & n.s. & n.s. \\
\hline Divers & ++ & n.s. & n.s. & ++ & n.s. & n.s. & ++ & n.s. & ++ & n.s. & n.s. & n.s. \\
\hline Administrators & n.s. & n.s. & n.s. & n.s. & n.s. & n.s. & + & n.s. & ++ & n.s. & n.s. & n.s. \\
\hline Scientists & + & n.s. & n.s. & n.s. & n.s. & n.s. & + & n.s. & + & n.s. & n.s. & n.s. \\
\hline Others & n.s. & n.s. & n.s. & n.s. & n.s. & n.s. & + & n.s. & + & n.s. & n.s. & n.s. \\
\hline
\end{tabular}

bio-diversity; being also able to aggregate marine fauna, and the structures are more likely to attract local fishermen than other users. The use of local fishing vessels at the reef area was considered an environmental positive impact once it is recogni-

Table 6 The top and bottom impacts due the existence of the ARs. Stakeholders' rating averages are indicators of their sensitiveness to each item. Ratings vary between 1.0 (minimum), and 5.0 (maximum). Legend: CF, Commercial fishermen associations; RF, anglers associations and clubs; sed as a more sustainable way of fishing, when compared with larger vessels. There are other positive impacts perceived as having the potential to augment catch rates when fishing in the reef area.

DV Divers clubs; AD, Administration bodies in fisheries, environment, and fisheries funds managers; SC, Natural and social scientists, and OI, Other institutions as local council representatives in the fisheries and/or environment sectors)

\begin{tabular}{|c|c|c|c|c|c|c|c|c|c|c|}
\hline \multirow{2}{*}{$\begin{array}{l}\text { Rank } \\
\text { Top } 10\end{array}$} & \multirow[t]{2}{*}{ ARs' positive impacts } & \multirow[t]{2}{*}{ Dim } & \multirow[t]{2}{*}{ Score } & \multicolumn{7}{|c|}{ Stakeholder rating averages } \\
\hline & & & & All & $\mathrm{CF}$ & $\mathrm{RF}$ & DV & $\mathrm{AD}$ & $\mathrm{SC}$ & $\mathrm{OI}$ \\
\hline 1 & To promote bio-diversity & ENV & 204 & 4.6 & 4.1 & 4.4 & 4.7 & 5.0 & 4.6 & 4.6 \\
\hline 2 & $\begin{array}{l}\text { To contribute for the success in fish enhancement } \\
\text { actions }\end{array}$ & ENV & 192 & 4.4 & 4.6 & 3.9 & 4.3 & 4.3 & 4.5 & 4.6 \\
\hline 3 & To aggregate marine fauna & ENV & 190 & 4.3 & 4.0 & 4.1 & 5.0 & 4.3 & 4.1 & 4.1 \\
\hline 4 & $\begin{array}{l}\text { To increase the numbers of local fishing vessels in the } \\
\text { AR area }\end{array}$ & ENV & 188 & 4.3 & 4.3 & 4.3 & 4.5 & 4.4 & 4.1 & 4.1 \\
\hline 5 & $\begin{array}{l}\text { To increase the numbers of recreational anglers } \\
\text { in the area }\end{array}$ & ENV & 187 & 4.2 & 4.0 & 4.3 & 4.2 & 4.4 & 4.4 & 3.9 \\
\hline 6 & To protect juveniles from inshore waters & ENV & 186 & 4.2 & 4.6 & 4.3 & 3.7 & 4.4 & 4.1 & 4.3 \\
\hline 7 & To demonstrate to users that the program is worthy & $\mathrm{SOC}$ & 182 & 4.1 & 4.0 & 4.1 & 4.2 & 4.0 & 4.3 & 4.3 \\
\hline 8 & To augment the catch in the AR area & $\mathrm{ECO}$ & 181 & 4.1 & 4.3 & 4.0 & 4.0 & 4.0 & 4.1 & 4.3 \\
\hline 9 & To protect some marine life species & ENV & 178 & 4.0 & 3.7 & 4.1 & 4.2 & 3.4 & 4.5 & 4.4 \\
\hline 10 & To increase the numbers of more divers in the area & ENV & 175 & 4.0 & 4.1 & 4.0 & 4.3 & 3.8 & 4.4 & 3.4 \\
\hline 10 & To attract users to the near area & $\mathrm{SOC}$ & 175 & 4.0 & 4.0 & 3.6 & 4.0 & 4.1 & 4.3 & 3.9 \\
\hline Bottom 10 & ARs' negative impacts & & & & & & & & & \\
\hline 1 & To increase the need of sea rules accomplishment & $\mathrm{SOC}$ & 83 & 1.9 & 2.7 & 2.0 & 1.5 & 1.6 & 1.9 & 1.6 \\
\hline 2 & To increase fishing pressure over the AR & ENV & 94 & 2.1 & 2.0 & 1.9 & 2.3 & 2.3 & 2.3 & 2.1 \\
\hline 3 & To augment fishing gears lost near the AR & ENV & 109 & 2.5 & 1.9 & 2.1 & 1.8 & 2.8 & 2.9 & 3.1 \\
\hline 4 & To contaminate or pollute the water & ENV & 110 & 2.5 & 3.0 & 2.7 & 2.3 & 2.3 & 2.8 & 2.0 \\
\hline 5 & To increase local authorities enforcement & SOC & 115 & 2.6 & 2.6 & 2.6 & 2.5 & 2.6 & 2.3 & 3.1 \\
\hline 6 & To cause more fishing gears damages & $\mathrm{ECO}$ & 116 & 2.6 & 2.0 & 3.1 & 2.0 & 2.6 & 2.8 & 3.1 \\
\hline 7 & To find out other less expansive alternatives & $\mathrm{ECO}$ & 120 & 2.7 & 3.1 & 2.9 & 2.2 & 3.3 & 2.6 & 2.3 \\
\hline 8 & To make no contribution to social benefits & $\mathrm{SOC}$ & 123 & 2.8 & 2.6 & 3.0 & 3.0 & 2.3 & 3.4 & 2.6 \\
\hline 8 & $\begin{array}{l}\text { To generate conflicts between fishermen and } \\
\text { anglers }\end{array}$ & SOC & 123 & 2.8 & 2.6 & 3.0 & 2.3 & 2.6 & 3.3 & 2.9 \\
\hline 8 & $\begin{array}{l}\text { To realise that there were better sites to deploy } \\
\text { ARs }\end{array}$ & $\mathrm{ECO}$ & 123 & 2.8 & 2.7 & 2.9 & 2.8 & 3.1 & 2.6 & 2.6 \\
\hline
\end{tabular}


Negatively, the worst impact perceived is the lack of enforcement measures to keep sea use rules in the deployment area. Other negative impacts relate to the uncontrolled augmentation of fishing pressure on the reefs, associated especially with the activities of non-local boats having more powerful fishing capacity. Other perceived adverse impacts include the belief that ARs cause a loss of fishing gear which in turn entails additional costs in their replacement.

\section{Discussion}

This study shows that the deployment of the Algarve's reef structures has resulted in perceived changes. The program can be considered successful since, apart from few sceptic views, in general key-stakeholders do not oppose to it and indeed there is an overall positive attitude. For the purposes of this study key-stakeholders can be considered as licit 'judges' of the AR program by virtue of their experience, use or knowledge of these structures. Among the key-stakeholders panel it is agreed that, compared to the economic or social dimensions, the environmental dimension seems to be the one impacted most positively. The social dimension can be seen as the one that still remains relatively unaffected by reef deployment, either for better or worse. Moreover, it seems that there are no highly adverse (i.e., impacting negatively) factor-sets, whatever the dimension. The negative effects are specific and relate to the risk of losing gears, conflicts between users, and problems of enforcement. Arguably these can all be overcome through awareness campaigns on how to use the ARs. By its turn, as recommended by Murray \& Betz (1994). A slightly unexpected result is that, despite the scientific evidence of increased economic abundance, some stakeholders take a cautious position regarding the economic impacts in the belief that there are no strong signs of visible positive results.

Biological findings show that AR structures are intensely colonised and attract fish assemblages. Monitoring data show that there is an average increment on catches (Santos \& Monteiro, 1997, 1998). However, some potential users consider ARs' siting to be generally either unknown or of no interest. The latter situation may arise where, even if the underwater structures are detected by vessels, the quantity of harvested fish is deemed inadequate or the species composition unsuitable; consequently, the site fails to be accepted as a 'hot spot' ground amongst other fishermen. A further constraint on the effectiveness of ARs is that their use may be limited to commercial fishermen who use passive gears (as pots, traps, trammel and gillnets, etc.). Eco-tourism based around charter boats and diving is an activity that could take some advantage from reef deployment, and in particular the depth and range once they are additional features to charter boat passengers or to divers. Due the ARs' depth range, the structures can be used for several levels of divers.

ARs are also a tool to manage coastal resources insofar as they can bring about a spatial separation between inshore fishing vessels, which are attracted to the reef areas, and the more powerful commercial fishing gears (such as trawl and pelagic purse-seine) which are in effect excluded. In addition, considering that the catch can be augmented in the reef area and assuming that the access to the resources is facilitated, exploitation costs can be reduced. Economic impacts usually presuppose a change expressed by a multipliereffect in output, revenues, and employment. However, while catches and income may well have increased as a direct consequence of deploying these structures, key-stakeholders seem unconvinced about employment effects, i.e. ARs are not believed to make a notable contribution to the number of jobs created in the nearby areas. Whether this is the case de facto is not clear, since even though the construction of the reefs contributed to an increase on labour for a certain period of time, there is no firm evidence for employment creation within the fisheries. This is consistent with the results of the study by Kovács (2000). Besides, a sustained increase in economic benefits arising from AR deployment depends crucially on how access is managed, and failure to restrict the number of users may result in stock depletion and a cancelling of any long-term economic gains (Whitmarsh \& Pickering, 1999).

A joint collaboration between several keystakeholders is important in order to know to 
what extent the impact of the ARs is perceived. A problem that is being faced is the specificity of the AR program. Many stakeholders were consulted before and during the deployment phase, and even after deployment many of the results seem to be based on expectations. This study demonstrates how the key-stakeholders perceptions of the impacts may be empirically measured. By using a summated rating scale and appropriate simple statistics it is possible to make a selection of the most important positive and negative impacts from the entire item-pool. The panel members who took part of the survey emphasised that in the future they would like to be consulted in similar surveys. This is a sign of positive interdisciplinary interest and participation in solving fisheries management problems. Finally, it can be added that these sorts of survey can give some information to fisheries managers about stakeholders' positioning, which can be used as indicators for management. It is important to get more people involved with the reefs use and awareness campaigns towards each user type in particular should be carried out in the future.

Acknowledgements The authors would like to thank the collaboration of the entities involved in answering the questionnaire. The first author is grateful to the Portuguese Foundation for Science and Technology (FCT) for providing funding for his $\mathrm{PhD}$ studies $(\mathrm{PhD}$ grant reference \# SFRH/BD/6197/2001). This study was supported by the MARE program, within the project Implantação e estudo integrado de sistemas recifais.

\section{References}

Aabel, J. P., S. Cripps \& G. Kjeilen, 1996. Oil and gas production structures as artificial reefs. European artificial reef research. In Jensen, A. C. (ed.), Proceedings of the 1st EARRN conference, Ancona, Italy, 391-404.

Bell, J., 1987. Doing Your Research Project: A Guide for First-Time Researchers in Education and Social Science. Open University Press, Buckingham.

Cripps, S. J. \& J. P. Aabel, 2002. Environmental and socioeconomic impact assessment of Ekoreef, a multiple platform rigs-to-reefs development. ICES Journal of Marine Science 59: S300-S308.

DGPA (Direcção Geral das Pescas e Aquicultura) 2000. As pequenas comunidades piscatórias do sul: descoberta de uma realidade... Plano de extensão pesqueira do sul - PEPE, DGPA (MADRP).
DGPA (Direcção Geral das Pescas e Aquicultura) 2002. Datapescas. 55 (Janeiro-Dezembro).

DGPA (Direcção Geral das Pescas e Aquicultura) 2004. Evolução da frota e pescadores das CPS (1998-2003).

Galvez, R. E., 1991. Some socio-economic issues in artificial reefs management: a case of Lingayen Gulf, Philippines. Tropical Coastal Area Management 6: 1-2.

Kennish, R., K. D. P. Wilson, J. Lo, S. C. Clarke \& S. Laister, 2002. Selecting sites for large-scale deployment of artificial reefs in Hong Kong: constraint mapping and prioritization techniques. ICES Journal of Marine Science 59: S164-S170.

Kovács, I., 2000. Os jovens e a renovação da pesca: expectativas e aspirações em relação ao trabalho e à vida profissional. In Moniz, A. B., M. M. Godinho \& I. Kovács, (eds), Pescas e pescadores: futuros para o emprego e os recursos. Celta Editora, Oeiras: 43-74.

McGurrin, J. M. \& A. J. Fedler, 1989. Tenneco II artificial reef project: an evaluation of Rigs-to-Reefs fisheries development. Bulletin of Marine Science 44: 777-781.

McKinnon, A. \& M. Forster 2000. Full report of the Delphi 2005 survey. European logistical and supply chain trends: 1999-2005. TRILOG consortium: TNO (Netherlands) (co-ordinators), Heriot-Watt University, Netherlands Economic Institute, Cranfield Centre for Logistics and Transportation, Chalmers Institute of Technology (Sweden), LaTTS (France).

Milon, J. W., 1989. Economic evaluation of artificial habitat for fisheries: progress and challenges. Bulletin of Marine Science 44: 831-843.

Milon, J. W., S. M. Holland \& D. J. Whitmarsh, 2000. Social and economic evaluation methods. In Seaman W. Jr. (ed.): Artificial Reef Evaluation with Application to Natural Marine Habitats, CRC press LLC, Boca Raton, Florida, 165-194.

Moniz, A. B. 1997. Construção de cenários para o sistema sócio-económico das pescas: o caso português. In Monteiro, C. C. (ed.), I Encontro internacional de Vilamoura sobre pescas, Vilamoura: 97-106.

Moniz, A. B., M. M. Godinho \& I. Kovács, 2000. Pescas e pescadores: futuros para o emprego e os recursos. Celta Editora, Oeiras.

Monteiro, C. C. \& M. N. Santos, 2000. Portuguese artificial reefs. In Jensen, A. C., K. J. Collins \& A. P. M. Lockwood, (eds.), Artificial Reefs in European Seas. Kluwer Academic Publishers, Dortrecht, 249-261.

Murray, J. D. \& C. J. Betz, 1994. User views of artificial reef management in the southeastern U.S. Bulletin of Marine Science 55: 970-981.

Reggio, V., V. Van Sickle \& C. Wilson, 1986. Rigs to reefs. Louisiana Conservationist 38: 4-8.

Reggio, V. C. 1989. Petroleum structures as artificial reefs: a compendium. 174. U.S. Minerals Management Service, OSC Study/MMS 89-0026.

Robson, C., 2002. Real World Research: A Resource for Social Scientists and Practitioner-Researchers, 2nd edn. Blackwell, Oxford.

Samples, K. C., 1989. Assessing recreational and commercial conflicts over artificial fishery habitat use: theory and practice. Bulletin of Marine Science 44: 844-852. 
Santos, M. N. \& C. C. Monteiro, 1997. The Olhão artificial reef system (south Portugal): fish assemblages and fishing yield. Fisheries Research 30: 33-41.

Santos, M. N. \& C. C. Monteiro, 1998. Comparison of the catch and fishing yield from an artificial reef system and neighbouring areas off Faro (Algarve, south Portugal). Fisheries Research 39: 55-65.

Santos, M. N. \& C. C. Monteiro 2001. The Portuguese experience on artificial reefs: past and future. In Coimbra, J. (ed.), NATO Science Series: Series A: Life Sciences Nieuwe Hemweg 6B Amsterdam 314: 281-294.

Ten Brink B. J. E., S. H. Hosper \& F. Colijn, 1991. A quantitative method for description and assessment of ecosystems: the AMOEBA approach. Marine Pollution Bulletin 23: 265-270.

Whitmarsh, D. \& H. Pickering 1999. Commercial exploitation of artificial reefs: economic opportunities and management imperatives. In Boncoeur, J. (ed.), Proceedings of the 9th annual conference of the European Association of Fisheries Economists EAFE: 66-83.

Whitmarsh, D., M. N. Santos, C. C. Monteiro \& J. Ramos, 2004. Economic measures of habitat improvement in marine fisheries and their conservation. Poster presented at the World Fisheries Congress, May 2-6, Vancouver, B. C.

Zar, J. H., 1996. Biostatistical Analysis, 3rd edn. Prentice Hall International Editions, Upper Saddle River, N. J. 